Mote: «Se a mulher se revolta contra o homem, nada fica intacto»

\title{
Nós, ainda hoje e mesmo
}

\section{Livia Apa \\ Universidade de Nápoles "L'orientale”}

Ao retomar as notas da minha apresentação no colóquio Novas Cartas, Novas Cartografias Re-configurando diferenças no mundo globalizado, que teve lugar em Évora em Março de 2014, senti o quanto aquela ocasião foi, antes de tudo, a possibilidade de explorar aquilo que em outros contextos se denomina "potencial multiplicador" de um livro como Novas Cartas Portuguesas. Com esta designação, como sabemos, na área dos estudos de "desenvolvimento", palavra abusada e demasiadas vezes encarada do ponto de vista de uma eurocêntrica ideia de progresso, define-se a capacidade de um determinado projecto/objecto se multiplicar num futuro mais ou menos longo, dentro de um conjunto de chamadas "boas práticas", capazes de garantir a sua própria duração e o seu próprio valor de uma forma duradoura, incidindo no contexto até implementar uma "mudança" de 
paradigma ao longo do tempo. Penso que é este efeito de multiplicação que um livro tão interligado ao conceito de rotura como Novas Cartas Portuguesas contém.

A sua capacidade de subversão da ordem, a do cânone literário, a do género literário, a da moral pública e privada de Portugal nos anos pré-revolução e de uma Europa batida por um necessário repensar do lugar da mulher na sociedade, foi, e é, de uma força arrasadora. Quem se aproxima pela primeira vez do livro não pode não ler, antes de tudo, o seu potencial de fractura; não pode deixar de se perguntar: o que é, afinal, este livro? 0 livro "existe", em primeiro lugar, como um questionamento de muito daquilo que o leitor médio está habituado a ler. Uma espécie de "glosa" na interpretação que deste termo fez Eugeni d'Ors, enquanto leitura do tempo presente. Novas Cartas Portuguesas podem, assim, ser lidas como uma monumental e labiríntica glosa do património literário sobretudo português, tal como da contemporaneidade nacional entendida no seu potencial de releitura situada a partir de um lugar de enunciação feminino e de resistência.

Por todas estas razões, quando me foi lançado o desafio contido na frase "se a mulher se revolta contra o homem nada fica intacto", não pude deixar de situá-la dentro daquilo que é o meu contexto de práticas diárias: a sala de aula. Dou aulas numa Universidade do Sul de Itália, a Università degli Studi di Napoli “L’Orientale”, numa cidade onde ainda hoje 37 \% das mulheres estão oficialmente desempregadas ou ocupadas no circuito do chamado trabalho informal, para não dizer clandestino, e quase 25\% (percentagem que ultrapassa $40 \%$ em alguns bairros) desistem da escola por razões familiares ou porque ficam grávidas prematuramente. Na verdade, estas mulheres desistem do sistema escolar porque não reconhecem na formação e na aprendizagem um valor capaz de melhorar as suas condições de vida. A universidade onde ensino vive, por sua vez, uma espécie de dupla identidade: se por um lado, acolhe ainda a fama de ser uma Universidade progressista e de esquerda, onde mesmo na sala de aulas é permitida uma certa militância ou pelo menos o exercício do debate, por outro lado, é alimentada pela infindável série de reformas às quais foi, e está a ser, submetida a universidade italiana. A nossa faculdade de Letras e Línguas Estrangeiras e o nosso Departamento de Estudos Literários, Linguísticos e Comparados estão a tornar-se a cada dia que passa cada vez mais numa escola de línguas mais ou menos "inteligente" onde 
a literatura é uma opção e a parte cultural dos vários espaços linguísticos não é considerada parte integrante da formação curricular. Se antigamente a vocação da nossa universidade era um certo pioneirismo na promoção de um tipo de estudo das literaturas já muito aberto para a contaminação entre as diversas ciências sociais e para os estudos culturais e a mais moderna prática dos estudos comparados, hoje em dia temos ao nosso dispor 48 horas por semestre de didáctica frontal para cada disciplina, de forma a "formar" os alunos e em muitos casos trabalhando com turmas que ultrapassam a centena de inscritos. A ideia de que saber uma língua é sobretudo aprender de cor infinitas listas de verbos irregulares e excepções é o que recomendam os programas ministeriais, juntamente com os estudos linguísticos aplicados não tanto às macro-categorias do valor performativo da mesma produção linguística, mas apenas ao estudo informático dos corpora, do léxico, etc., etc., etc...

Neste quadro, tendo em conta o meu percurso ancorado nos estudos culturais, e enquanto responsável pela cadeira de língua portuguesa, para mim a área de estudos de tradução é um acto de pura negociação entre o que devia ser, o que é esperado e a tentativa muitas vezes desesperada de ampliar a dimensão e a reflexão do que é aprender uma língua estrangeira. Traduzir e pensar a tradução como espaço de hospitalidade "derridiana" do outro pode ser às vezes uma pequena revolução. Foi precisamente a partir desta perspectiva de tradução que decidi durante dois anos seguidos trabalhar no curso de mestrado com Novas Cartas Portuguesas: considerando que o livro representa um belo exemplo do tempo e da geografia dos diferentes tempos e dos diferentes registos da língua portuguesa.

A minha turma é composta sobretudo de mulheres, na maioria vindas da província. Muitas delas são a primeira geração de licenciados nas suas famílias de origem. Para completar o cenário, é preciso dizer que em Itália vivemos anos de um renovado assalto aos direitos das mulheres não apenas porque está a ser repensada mais uma vez a lei sobre o aborto, mas também e sobretudo porque os últimos vinte anos de política voltaram a promover uma imagem "decorativa” da mulher. E a crise faz o resto porque cada vez mais 
mulheres perdem o emprego e ficam em casa a tomar conta da família e quando se separam dos maridos/companheir@s voltam a viver em casa dos pais.

Neste contexto, Novas Cartas Portuguesas anunciavam-se à partida como um elemento de desordem e, de alguma maneira, como uma provocação. Ora, como sabemos e praticamos, assumir a diversidade a todos os níveis implica altos riscos. Para mim, o que foi surpreendente observar foi como o livro serviu quase de dispositivo de aprendizagem para o reconhecimento das próprias necessidades e dos próprios desejos. As perguntas durante as aulas eram sempre muitas e o debate, constante. $\mathrm{O}$ que foi o feminismo em Itália? Como se configurou ele? Como se configura ele hoje? Nós em Itália não tivemos a guerra colonial; mas não será que partilhávamos da mesma ordem patriarcal? Descobrir que o voto para as mulheres foi uma conquista relativamente recente devida à recentíssima história republicana do nosso País; descobrir que para o divórcio e o aborto foi necessário passarmos por dois referendos; comentar as diversas instâncias do movimento de 77 em Itália e as suas manifestações - foi atravessar algo simultaneamente recente e já muito antigo para alunos que têm em média pouco mais de vinte anos. Qual o legado hoje destas lutas naquela que substancialmente é a geração da maioria das mães de todos eles? É verdade então, ainda hoje, que como nos dizem as Três Marias "Se a mulher se revolta contra o homem - como se revoltou naqueles anos em Itália - nada fica intacto”?

0 potencial de subversão formal do livro foi o primeiro passo para partir para a descoberta daquilo que é quase o corolário do livro: a reivindicação de uma cidadania completa, de uma "egaliberté" e, parafraseando o título que escolhi para esta minha reflexão empírica, afirmar "nós, ainda agora e mesmo". Nós, as mulheres, enquanto portadoras de diferença ou, melhor ainda, como foi brilhantemente dito durante o congresso, enquanto reivindicadoras de variedade. Durante as aulas, todo o nosso percurso se construiu à volta do conceito de poder d@ leitor@, porque partimos da ideia de que ler um texto, e fazê-lo politicamente como tentamos fazer, quer dizer desfazê-lo, operando cortes, dobrando-o numa determinada direcção, privilegiando um percurso em vez de outro. Fazer a sua tradução.

Ler politicamente um texto quis dizer para nós, dia após dia, posicionar o próprio 
exercício de leitura perante o mundo e, no caso de alguns daqueles jovens, foi ainda possível posicionarem-se perante a sua própria vida. A minha pergunta de partida foi: o que acontece quando um livro como o Novas Cartas Portuguesas se apresenta como um texto à partida "desconstruído/desconstruível"? 0 que acontece quando a natureza essencialmente política do nosso sujeito/objecto discursivo se situa na sua irredutível heterogeneidade, na sua resistência tenaz a construir-se por um critério apenas de coerência, substância ou linearidade interna, chegando porém a materializar-se, partindo de uma ligação explícita com uma certa posição teórica ou política? Em suma, como atravessar um texto que recusa o estatuto de género literário sem o reificar nos confins de um determinado horizonte sobredeterminado, como diria Althusser? Encontramos a resposta no facto de Novas Cartas Portuguesas ser um texto proteiforme, como diria Franz Fanon, e, por natureza, convidativo ao exercício da fractura, advogando para si a potência do leitor exactamente pela sua capacidade de "passionare" - do latim patio, sofrer, ser submetido - quem o lê.

Não sei como os "meus meninos" e as "minhas meninas" responderiam a todas estas questões. Sei que eles todos, meninos e meninas, no Dia Oito de Março tinham uma frase das Novas Cartas no seu time-line do Facebook, tal como sei que na maioria dos casos e depois de terem defendido teses brilhantes sobre o livro, operaram corajosas mudanças nas suas vidas. Houve quem decidisse, mesmo na mais completa precariedade, ser mãe, quem decidisse praticar o exercício da escrita como objectivo a perseguir, quem decidisse ainda mudar de cidade ou de país. Aprendi muito com eles todos e a minha gratidão é infinita, porque me deram a oportunidade de voltar a viver a emoção do crescer através da leitura. E mais uma vez, se calhar e sobretudo, de me terem ensinado "o que pode a literatura" quando consegue explorar o seu potencial multiplicador em quem a lê e a ama. 
Livia Apa nasceu em 1963, em Nápoles. É investigadora junto da Università degli Studi di Napoli “ L'Orientale” e coordenadora científica da Cátedra Margarida Cardoso. Trabalha na área dos Estudos Culturais dos países de língua oficial portuguesa. É também tradutora, tendo publicado em italiano, entre outras, obras de José Eduardo Agualusa, Mia Couto, Ondjaki, Ruy Duarte de Carvalho, Florbela Espanca, Mário Cesariny de Vasconcelos, Ana Luísa Amaral e Ana Paula Tavares. 